\title{
Descriptive Research on SOCSO's Invalidity Pension Scheme (IPS) Claims Payment
}

\author{
Mohd Zaki Awang Chek, Isma Liana Ismail, Nur Faezah Jamal
}

\begin{abstract}
Social insurance was introduced in Malaysia in 1971 through Social Security Organization (SOCSO). Herein, this study describes the increasing trend amounts of SOCSO's IPS claims payment. This study analyzed IPS data from 2002-2014 to examine severity each of benefits offered such as Invalidity Pension, Survivors' Pension, Constant Attendance Allowance, Rehabilitation Benefit and Funeral Benefit. Furthermore, the registered number of employers had increased to approximately $5 \%$ in 2013. This is because SOCSO officers all around Malaysia had been actively searching for employers who have yet to register to make contributions for their eligible employees. Additionally, the total number of IPS claims payment had steadily increased since 2002 to 2014. On average, the total claims payment of IPS increased at a rate of $10 \%$ every year. This study suggested that a large part of the increase in IPS claims could be explained by population which active contributors, and the increase result from equalization of IPS services across the country. In addition, it seems that the claims of low and high care levels depend on different factors. The increase in IPS claims should be monitored carefully to identify underlying factors and to ensure sustainability of the funding system.
\end{abstract}

Keywords: Invalidity Pension Scheme, Descriptive Analysis, SOCSO, Social Insurance, Claims Payment.

\section{INTRODUCTION}

Social Security Organization (SOCSO), was established in 1971 to provide social insurance and protections such as Employment Injury Scheme (EIS) and Invalidity Pension Scheme (IPS) to all employees in Malaysia [1]. The source of employers and the employees. Employees who draw a monthly salary not exceeding RM4,000 are required to contribute. Those who have neither registered nor contributed, and earn more than RM4,000 per month, are given the option to register and contribute, with the condition that an agreement is entered between employee and employer. Based on the 'once-in-always-in' principle, once an employee is eligible under the ESSA 1969, he or she continues to be eligible to contribute, regardless of the amount of his or her monthly salary [2]. The updated number of active contributors in SOCSO is introduced in this subtopic in order get better idea of the employment in Malaysia.

Revised Version Manuscript Received on September 16, 2019.

Mohd Zaki Awang Chek, Faculty of Computer and Mathematical Sciences, Center for Actuarial Studies, Universiti Teknologi MARA, Tapah, Perak, Malaysia.

Isma Liana Ismail, Faculty of Computer and Mathematical Sciences, Center for Statistics and Decision Science, Universiti Teknologi MARA, Tapah, Perak, Malaysia.

Nur Faezah Jamal, Faculty of Computer and Mathematical Sciences, Center for Statistics and Decision Science, Universiti Teknologi MARA, Tapah, Perak, Malaysia. SOCSO's collection comes from both parties, namely the

Table 1: Number of registered employers and employees 2002-2014 [14]

\begin{tabular}{|c|c|c|c|c|c|}
\hline & \multicolumn{5}{|c|}{ 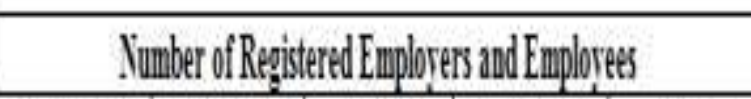 } \\
\hline I & $\begin{array}{l}\text { Walaysian } \\
\text { Popplanion }\end{array}$ & 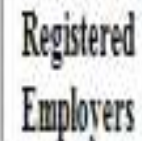 & $\begin{array}{l}\text { detirie } \\
\text { Emplores }\end{array}$ & $\begin{array}{l}\text { Regigstere } \\
\text { Emploves }\end{array}$ & $\begin{array}{l}\text { Actirer } \\
\text { Emplore }\end{array}$ \\
\hline !? & $24,00,000$ & 97,150 & 297,85 & $8,773,607$ & \\
\hline 13 & $4,90,000$ & 835 & 30,399 & & \\
\hline 4 & $15,60,000$ & & & & \\
\hline & $86,10,000$ & 58,3 & & & 32,0 \\
\hline 06 & $86,000,000$ & 6129 & & & 4,7 \\
\hline 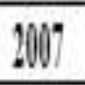 & $27,00,000$ & 601,603 & & & 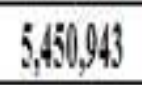 \\
\hline of 8 & $19,00,000$ & 684,465 & & & $3,600,02$ \\
\hline 09 & 900,000 & & & & \\
\hline & $88,00,000$ & & & & 3 \\
\hline & 0,000 & 819,9]: & & & 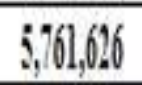 \\
\hline 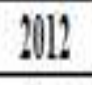 & $19,00,000$ & & & & \\
\hline & $20,00,000$ & & & 14,8 & 5,96, \\
\hline & $30,00,000$ & $951,1,8$ & & & 17, \\
\hline
\end{tabular}

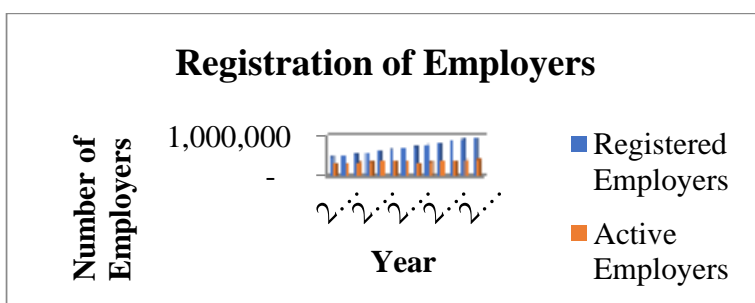

Fig. 1: Number of employers 2002-2014

Published By: 


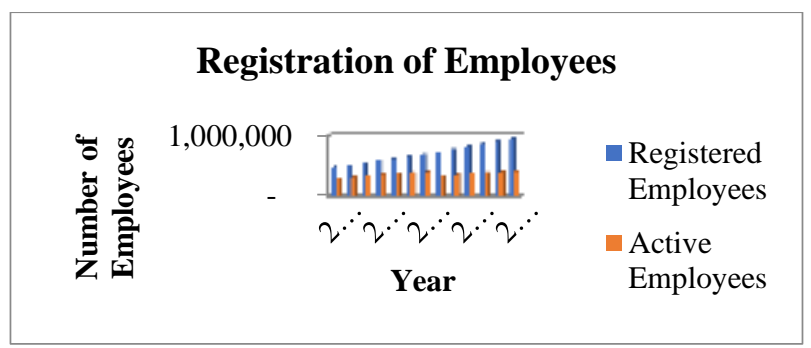

Fig. 2: Number of employees 2002 - 2014

Table 1 shows that the total Malaysian population was 30.2 million in 2014 compared to 24.4 million in 2002 . That gives an average annual population growth rate of 2.0 per cent for this 13 -year period. The population had steadily increased parallel to the number of active employers and employees. Throughout 2014, there was a steady increase in the number of registered employers and employees who were eligible under the ESSA 1969. Correspondingly, the number of registered employees had increased by $3.57 \%$ to 15.3 million compared to 14.82 million in 2013. The number of active employers also increased by $2.57 \%$ to 403,393 in 2013 , while the number of active employees increased by $3.61 \%$ in 2014 as shown in Table 1, Fig. 1 and 2. The registered number of employers had increased to approximately 5\% in 2013. This is because SOCSO officers all around Malaysia had been actively searching for employers who have yet to register to make contributions for their eligible employees [3].

An Insured Person shall be considered as suffering from invalidity by reason of specific morbid condition of permanent nature either incurable or is not likely to be cured and no longer capable of earning, by work corresponding to his strength and physical ability, the scheme provides 24-hour coverage to employee who suffers from invalidity or death due to any cause and not related to his employment. Table 2 shows the total number of recipients for all types of benefits and the total number of IPS recipients.

Table 2: Total number of SOCSO and IPS recipients, from 2002 to 2014

\begin{tabular}{|r|r|r|}
\hline Year & IPS Recipients & $\begin{array}{r}\text { Total } \\
\text { Recipients }\end{array}$ \\
\hline 2002 & 146,950 & 261,900 \\
\hline 2003 & 141,348 & 251,888 \\
\hline 2004 & 155,564 & 268,663 \\
\hline 2005 & 159,044 & 264,640 \\
\hline 2006 & 170,972 & 272,367 \\
\hline 2007 & 182,864 & 290,463 \\
\hline 2008 & 190,941 & 298,068 \\
\hline 2009 & 211,519 & 324,798 \\
\hline 2010 & 230,883 & 351,433 \\
\hline 2011 & 249,239 & 378,377 \\
\hline 2012 & 262,529 & 397,541 \\
\hline 2013 & 541,193 & 681,017 \\
\hline 2014 & 564,147 & $1,166,632$ \\
\hline
\end{tabular}

Table 2 shows that there was a drastic increase of $72.19 \%$ from 681,017 in 2013 to $1,166,632$ in 2014 , which amounts to an additional 485,615 recipients. This can be attributed to the introduction of the Health Screening Programme. Additionally, the total number of IPS recipients had steadily

increased since 2002 to 2014. On average, the total number of IPS recipients increased at a rate of $62 \%$ every year.

\section{LITERATURE REVIEW}

The regression analysis approach predicts the path and the strength of a correlation that involves two variables; $\mathrm{X}$ and $\mathrm{Y}$, whereby $\mathrm{X}$ is an independent variable while $\mathrm{Y}$ is dependent [4]. As such this section unfolds the discussion of several researches pertaining to collection of funds and payments of claims practiced by both the governmental and non-government insurance industry. Furthermore, the approaches of descriptive and regression have been employed by these studies in examining data, besides estimating the results of fund collection, as well as expenses [5]. As such, the descriptive method was employed in comparing the costs of treatment for recipients of hospice with non-recipient patients suffering from cancer seven month before demise. Nevertheless, long-term eligibility and improvement in quality due to provision of benefits are some of the noted significances. Other than that, [6] asserted that the type and the amount of healthcare services offered within the period before death are given more emphasis due to the general belief that patients at deathbed receive more dedication. The descriptive analysis demonstrated that the Medicare expenses increased to $\$ 13,316$ in 1988 for a person from $\$ 3,488$ in 1976 . Furthermore, payments made to those surviving by Medicare saw a slight adjustment that fluctuated within the range of $27.2 \%$ to $30.6 \%$ at the time of the study. The impacts of a hospice event upon Medicare Part A expenses for the initial three years [7]. As a conclusion, based on the descriptive and regression analyses, some aspects were found to be present that affected the total expenses of Medicare, which further influenced the care given for survivors and deceased.

\section{METHODOLOGY}

The descriptive statistics, inferential statistics and optimization simulation procedures was conducted with Microsoft Excel and SPSS computer package. Descriptive analysis is used to describe the basic features of the data in this study. They provide simple summaries of the data and the measures. Together with simple graphics, they form the basis of virtually every quantitative analysis of data [8].

The use of descriptive and summary statistics has an extensive history and the simple explanations of populations. There are three major characteristics of a single variable that are often observed: the distribution, the central tendency and the dispersion. All three characteristics are described accordingly in this study. The distribution is a summary of the severity of individual values for a variable. The most common way to describe a single variable is severity distribution. Severity distributions can be illustrated in two ways, as a table or as a graph. Distributions may also be displayed using percentages. In this study, the variables measured was severity of SOCSO's IPS contribution collection as well as claim payments. 
The central tendency of a distribution is an estimate of the "center" of a distribution of values. There are three major types of estimates for central tendency, namely mean, median, and mode. The mean or average is probably the most commonly used method for describing central tendency. To compute the mean, all one has to do is add up all the values and divide the total by the number of values. The median is the score found at the exact middle of the set of values [9].

This study measures the severity of contribution collection as well as claim payments. On top of that, Microsoft Excel software is used to perform the data analysis [10].

\section{RESULTS AND DISCUSSION}

\section{Severity of invalidity pension and grant benefit}

The following Fig. 3 shows the frequency and severity trends of the Invalidity Pension and Grant benefit from 2002 to 2014 respectively. In line with the increasing number of recipients, the total sum of payments for Invalidity Pension and Grant was increased by RM44.22 million or $9.53 \%$, from RM453.65 million in 2013 to RM497.82 million in 2014.

\section{Severity of Invalidity Pension and Grant}

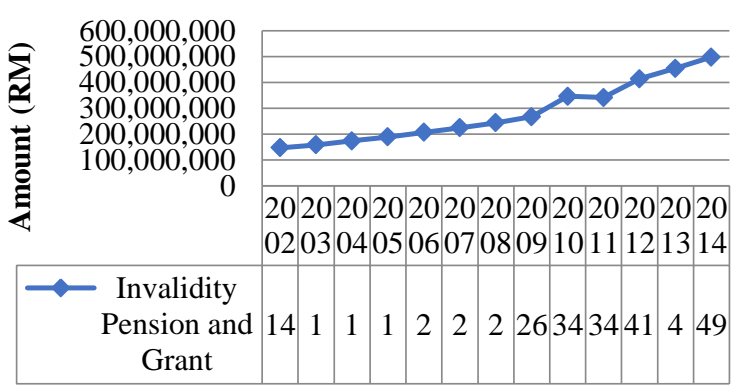

Fig. 3: Severity of invalidity pension and grant from 2002 to 2014

\section{Severity of Survivor Pension (SP) benefit}

The following Fig. 4 shows the severity patterns of the Survivors' Pension (SP) from 2002 to 2014. The total payment for Survivors' Pension in 2014 had increased by RM62.68 million or $8.22 \%$ to RM824.879 million compared to RM762.20 million in the previous year.

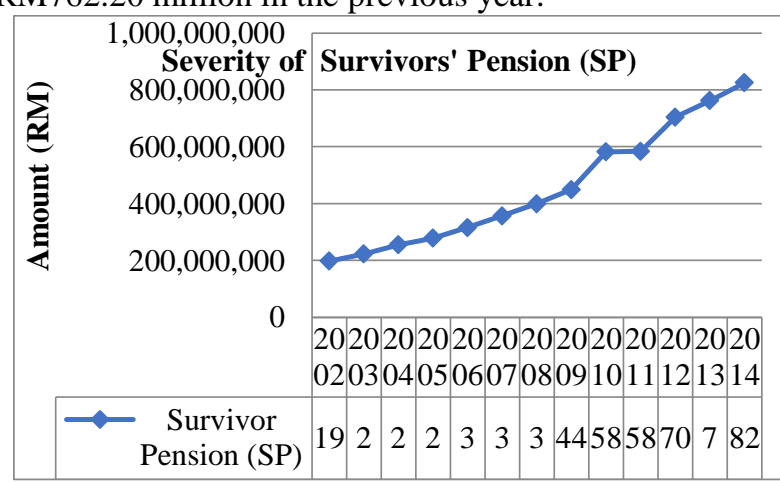

Fig. 4: Severity of survivors' pension from 2002 to 2014

Severity of Constant Attendance Allowance (CAA) benefit

The following Fig. 5 shows the severity trends of Constant Attendance Allowance (CAA) Benefit from 2002 until 2014. The total payment for Constant Attendance Allowance had increased by $28 \%$ or RM 5.884 million to RM 26.947 million in 2014 compared to RM 21.063 million in the previous year.
However, the trend shows that it had drastically increased in 2012 due to the full claim payments to eligible claimants [11].

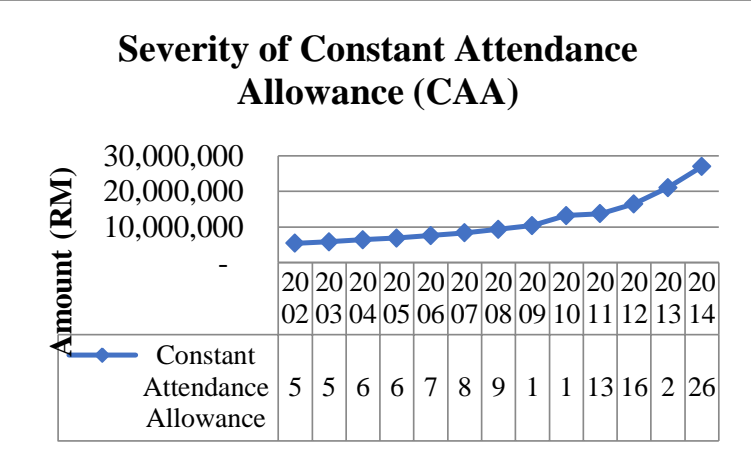

Fig. 5: Severity of constant attendance allowance from 2002 to 2014

\section{Severity of Rehabilitation Benefit $(R B)$}

Fig. 6 shows the severity patterns of the Rehabilitation Benefit (RB) from 2002 until 2014. The total expenditure for the Rehabilitation Benefit had increased by $18 \%$ from RM135 million to RM159.28 million in 2014. Additionally, the amount of claim payments had also drastically increased in 2011.

\section{Severity of Rehabilitation Benefit (RB)}

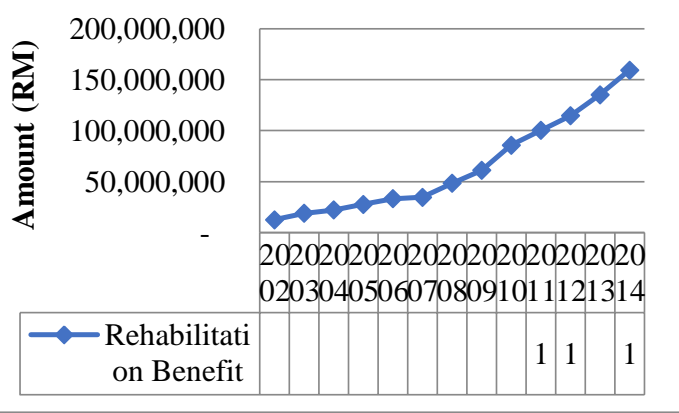

Fig. 6: Severity of Rehabilitation Benefit (RB) from 2002 to 2014

\section{Severity of Funeral Benefit (FB)}

The following Fig. 7 shows the severity trends of Funeral Benefit (FB) from 2002 until 2014. A total of 15,789 recipients were paid the Funeral Benefit, amounting to RM18.6 million in 2014. This amount showed an increase of RM3.168 million or $20 \%$ compared to RM15.5 million paid to 12,980 recipients in 2013 . The trends showed gradual increase each year. The claim for this benefit is fixed at RM500 for eligible insured persons. The claim will be paid through the nominee's bank account, which must be registered with the SOCSO Office. Beneficiaries who fulfil the requirements set by the ESSA 1969 are eligible for the Survivors' Pension claim [11]. 


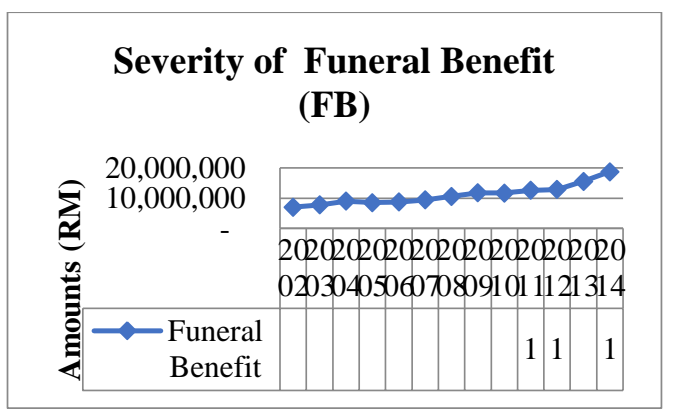

Fig. 7: Severity of Funeral Benefit (FB) from 2002 to 2014

\section{Severity of education benefit}

The holistic picture on types of benefits being paid to the recipients, the Education Benefit is also presented. However, this benefit was not included in the calculation for the Actuarial Present Value (APV) because this benefit is offered in terms of loan and conversion to scholarship. In addition, all the amounts spent on this Education Benefit were taken from SOCSO's free reserve account [12]. Fig. 8 shows the severity of the Education Benefit from 2005 to 2013. The most recent data are currently unavailable due to the confidentiality of the information. In 2012, an amount of RM6,538,686 was approved as education loan benefits for 211 borrowers, who are children of insured persons in receipt of SOCSO's benefits [13]. However, in 2009, the number of education benefit recipients had significantly dropped because most of the applications failed to fulfil the requirements set by SOCSO. Since it was first introduced in 1997, RM70,000,000.00 worth of loans were granted to 5,000 applicants who met the requirements set by SOCSO were approved. The levels of the courses pursued were Certificate, Diploma, and bachelor's degree. In addition, RM7,085,891.00 was paid periodically to 200 local and foreign universities in 2013. To encourage students to excel in their studies, as previously mentioned, SOCSO has allowed the Education Loan Benefit to be converted to scholarships for students who obtained first class honours in their Bachelor's degree [14].

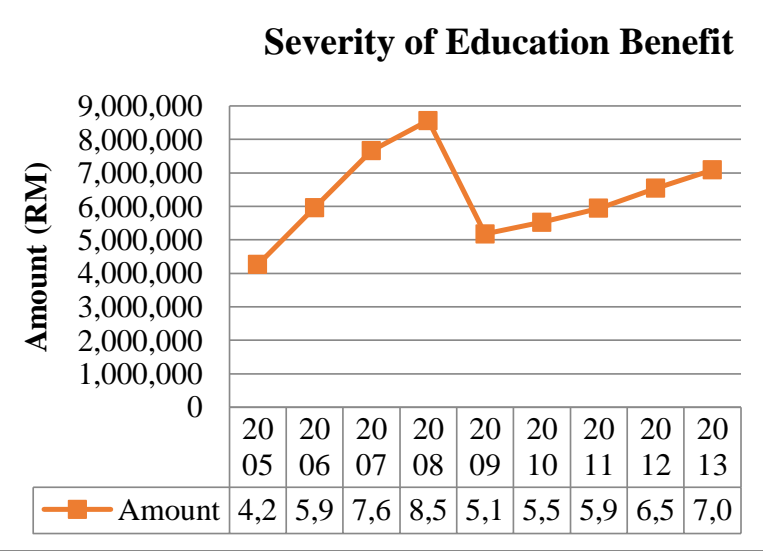

Fig. 8: Education benefit payment from 2005 to 2013

\section{CONCLUSION}

The above analyses were done as preliminaries to model an efficient social insurance plan. This is important and SOCSO should place emphasis on this. In this study also, the frequency analysis based on available past information it concerns the frequency exposure to risk. Furthermore, the contribution fund collection and budgeted claim amounts were used as the basis to model an adequate contribution rate for SOCSO's IPS for further study [15].

\section{ACKNOWLEDGMENT}

This study was partially supported by UiTM Perak Branch. We thank our colleagues from Universiti Kebangsaan Malaysia (UKM) and Social Security Organization (SOCSO) who provided insight and expertise that greatly assisted the study. We thank Prof. Dr. Zuriah Ab. Rahman for assistance, and Prof. Dr. Nuriszura Ismail for comments that greatly improved the manuscript.

\section{REFERENCES}

1. N. M. N. Muhammad, Personal Financial Planning. Selangor: UiTM Press, 2013.

2. S. C. Seng, Social security: Challenges and issues Available:

http://swrc.um.edu.my/social-security-challenges-and-iss ues/.

3. J. Mohd Rohani, A. Mohd-zainal, M. F. Johari, R. Md Sirat, R. Md. Zein, and I. Abdul Rahman, "Analysis of compensation cost related to Musculoskeletal Disorders (MSDs) against younger and older malaysian manufacturing workers," International Conference on Industrial Engineering and Operations Management, 2016, pp. 1699-1702.

4. M. H. Kutner, C. J. Nachtsheim, and J. Neter, Applied Linear Regression Models. Singapore: McGraw-Hill, 2008.

5. A. Venema, A. Bloemhoff, J. F. Ybema, and C. A. Stam, "Monitoring occupational accidents in the Netherlands: Does it work for prevention?," Saf. Sci. Monit., 11(2), 2007, pp. $1-8$.

6. J. D. Lubitz and G. F. Riley, "Trends in Medicare payments in the last year of life," N. Engl. J. Med. 328(15), 1993, pp. 1092-6.

7. D. Kidder, "The effects of hospice coverage on medicare expenditures," Health Serv. Res., 27(2), 1992, pp. 195-217.

8. L. Xiong, L. Zhang, W. Tang, and Y. Ma, "Constructing an urban population model for medical insurance scheme using microsimulation techniques," Comput. Math Methods Med., 2012, pp. 1-14.

9. G. C. Taylor, Regression models in claims analysis. Available: http://www.beanactuary.org/pubs.pdf.

10. D. C. Montgomery, E. A. Peck, and G. G. Vining, Introduction to Linear Regression Analysis. New Jersey: John Wiley and Sons, 2006.

11. Social Security Organisation (SOCSO), Home. Available: https://www.perkeso.gov.my/index.php/en/.

12. SOCSO, SOCSO annual report 2013. Available: https://www.perkeso.gov.my/images/laporan_tahunan/La poran_Tahunan_2013.pdf.

13. M. Hashim, Personal Financial Planning. Selangor: UiTM Press, 2013

14. SOCSO, SOCSO annual report 2011. Available: https://www.perkeso.gov.my/images/laporan_tahunan/La poran_Tahunan_2011.pdf.

15. R. Kaas and M. Goovaerts, Modern actuarial risk theory: Using R. Berlin: Springer Science and Business Media, 2008. 